\title{
A RARE CASE OF VASCULAR HAMARTOMA OF NASAL CAVITY
}

\author{
Sathyaki D.C1, Jyothi Swarup. R², Mohan $\mathrm{M}^{3}$, Mamatarani Rout ${ }^{4}$, Manjunath.K ${ }^{5}$
}

\section{HOW TO CITE THIS ARTICLE:}

Sathyaki DC, Jyothi Swarup R, Mohan M, Mamatarani Rout, Manjunath K. "A rare case of vascular hamartoma of nasal cavity". Journal of Evolution of Medical and Dental Sciences 2013; Vol2, Issue 35, September 2; Page: 6656-6658.

ABSTRACT: Sinonasal tract is complex anatomical site with a large list of possible diagnoses. Most common ones being sinonasal polyposis and papillomas. Occasionally there may be mass lesions that are difficult to conclude. This case report describes one such case where it was difficult to conclude.

INTRODUCTION: The sinonasal tract is home to a dizzying array of reactive, benign neoplastic and malignant entities and differentiating these can be difficult owing to the limited nature of biopsies from this site that are encountered in E.N.T practice. Most of these consist of inflammatory polyps, papillomas and squamous cell carcinomas. Other diagnoses such as salivary type tumors, olfactory neuroblastomas and poorly differentiated carcinomas may occasionally be seen but are familiar to most E.N.T surgeons. The diagnosis becomes more complicated when a biopsy or polypectomy yields a low grade glandular proliferation. In such circumstances the diagnosis should include hamartomas ${ }^{1}$.

CASE REPORT: A 29 year old female patient presented with long standing nasal obstruction. Anterior rhinoscopy showed a pinkish grape like mass which was insensitive to touch and did not bleed on touch. Diagnostic nasal endoscopy showed a pinkish mass in the left middle meatus which was arising from the maxillary sinus and was extending towards choana. It was suggestive of sinonasal polyposis.

Patient underwent endoscopic polypectomy with middle meatal antrostomy and the tissue sent for histopathological examination was suggestive of sinonasal polyposis, but after one year patient presented with sudden onset of bleeding from left nasal cavity and nasal obstruction on the same side. On diagnostic nasal endoscopy a pink polypoidal mass, friable, bleeds on touch, covered with yellowish cheesy debris seen completely occupying the left nasal cavity. Computed tomography showed heterogenous opacity with calcified spicules occupying the left maxillary sinus and the osteomeatal complex extending to left nasal cavity. A provisional diagnosis of fungal rhinosinusitis was made.

Patient underwent endoscopic debridement. Profuse haemorrhage was encountered during debridement. The lesion showed friable mass with yellowish, cheesy and foul smelling debris. Complete clearance of the mass from nasal cavity and maxillary sinus achieved.

Histopathological examination showed well defined fibro-collagenous tissue capsule with areas of haemorrhage and large number of vascular spaces of varying size lined by endothelial cells. The lumen showed haemorrhage with fibrinoid necrosis at places. Features were suggestive of Vascular Hamartoma. 
DISCUSSION: Vascular hamartomas are defined as disorganized and excessive proliferations of vascular tissue which, due to their limited growth, are considered developmental malformations rather than true neoplasms. Usually, the use of the term "hamartoma" implies the presence of the lesion at birth, with subsequent growth paralleling that of the animal but ceasing with maturity. Vascular hamartomas are classified as capillary telangiectasis, cavernous angiomas, and arteriovenous or venous malformations. The clinical significance of hamartomas is generally attributed to their potential to spontaneously bleed. Histochemistry and immunohistochemistry were used as additional tools to further define vessel structure and the relationship between the vessels of each hamartoma with the surrounding structures ${ }^{2}$.Hamartomas are usually congenital and simultaneously grow along the rest of the body. Once they reach their adult size they do not extend to involve more tissue unless there is trauma, infections, oedema, inflammation and filling of new vascular channels ${ }^{3}$. They are common in lung, liver, kidney, spleen and intestine but are extremely rare in the upper aerodigestive tract. Dicarlo et al reported a respiratory epithelial adenomatoid hamartoma in the maxillary sinus ${ }^{4}$. Fleming etal reported a case of sinonasal sero mucinous hamartoma ${ }^{5}$. Head and Neck surgeons should be aware of this pathological entity as a differential diagnosis for inverted papilloma and adenocarcinoma, in order to avoid unnecessary aggressive surgery. On the other hand misinterpretation as sinonasal polyposis may result in inadequate treatment ${ }^{4}$ therefore complete removal and compulsory histopathological examination of all the masses of nasal cavity should be followed as a strict protocol.

\section{BIBLIOGRAPHY:}

1. Weinreb I. Low grade glandular lesions of the sinonasal tract: A focussed review. Head and neck pathology. 2010; 4:77-83.

2. Smith SH, Winkle TV. Cerebrovascular hamartomas in five dogs. Veterinary pathology. 2001; 38:108-12.

3. Mishra MB, Bishen KA, Yadav A. Capillary haemangioma: An occasional growth of attached gingiva. Journal of Indian society of Periodontology. 2012 Oct; 16(4):592-6.

4. Carlo RD, Rinaldi R, Ottaviano G, Pastore A. respiratory epithelial adenomatoid hamartoma of the maxillary sinus: case report. Acta otorhinolaryngol ital. 2006; 26:225-7.

5. Fleming KE, Ordonez BP, Nasser JG, Psooy B, Bullock MJ. Sinonasal sero mucinous hamartoma: A review of literature and a case report with focal myoepithelial cells. Head and neck pathology. 2012; 6:395-9.

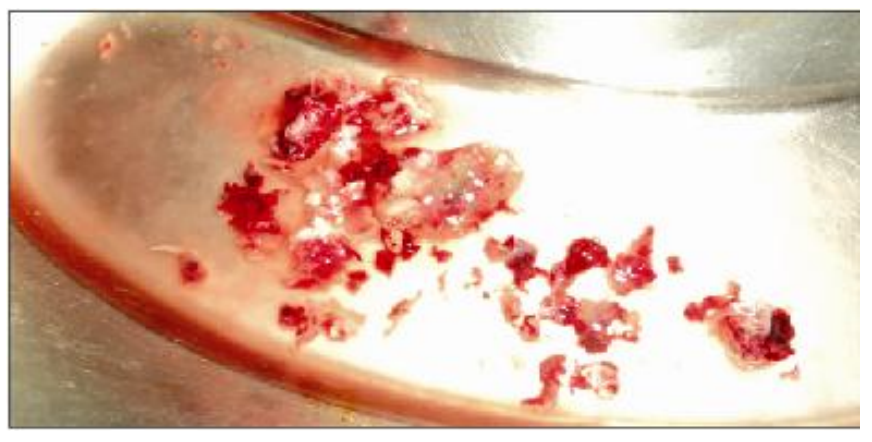

Fig-1: Gross specimen 


\section{CASE REPORT}

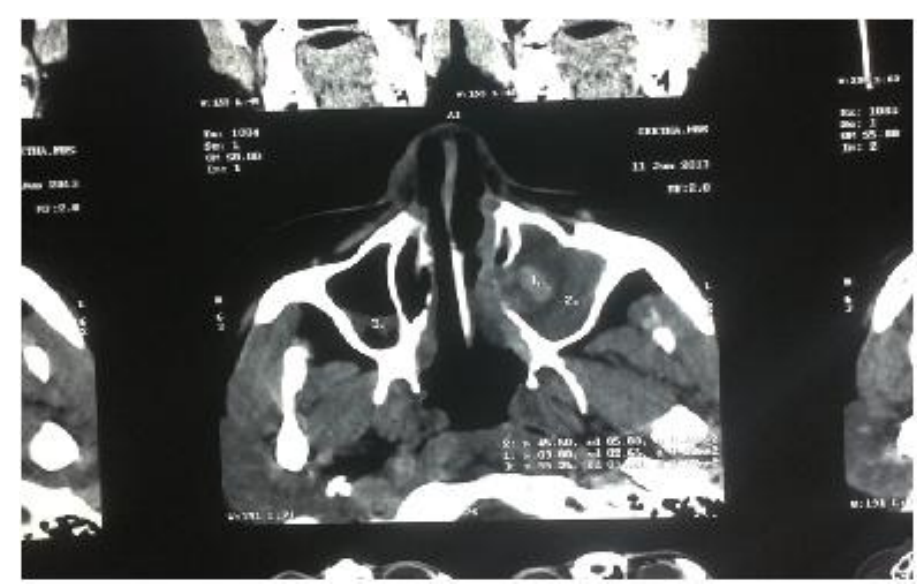

Fig-2: CT Scan

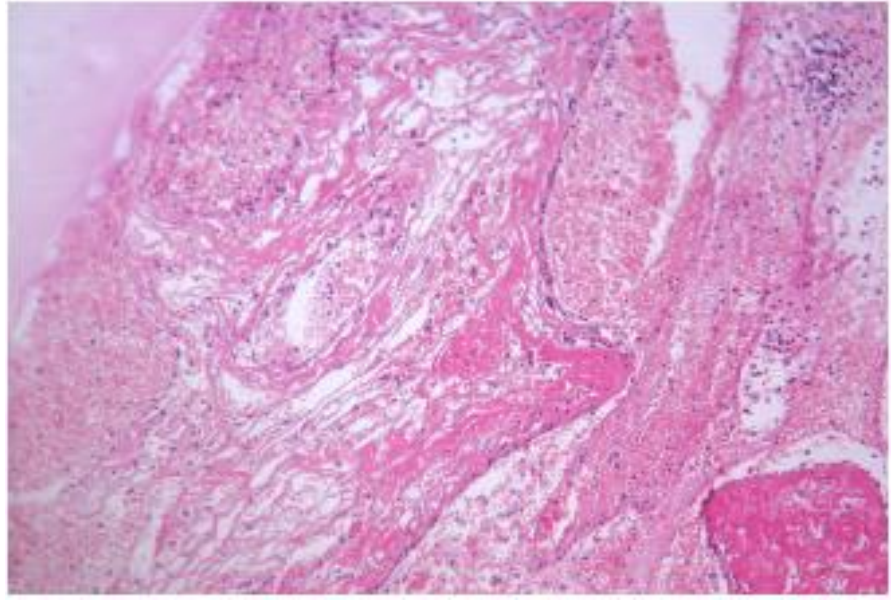

Fig-3 : Histopathology

\section{AUTHORS:}

1. Sathyaki D.C.

2. Jyothi Swarup R.

3. Mohan M.

4. Mamatarani Rout

5. Manjunath K.

\section{PARTICULARS OF CONTRIBUTORS:}

1. Assistant Professor, Department of E.N.T, Sri Siddhartha Medical College, Tumkur.

2. Associate Professor, Department of E.N.T, Sri Siddhartha Medical College, Tumkur.

3. Professor, Department of E.N.T, Sri Siddhartha Medical College, Tumkur.

4. Junior Resident, Department of E.N.T, Sri Siddhartha Medical College, Tumkur.
5. Junior Resident, Department of E.N.T, Sri Siddhartha Medical College, Tumkur.

\section{NAME ADRRESS EMAIL ID OF THE CORRESPONDING AUTHOR:}

Dr. Sathyaki D.C,

Department of E.N.T,

Sri Siddhartha Medical College,

Agalakote, Tumkur - 572107.

Email - sathyaki_dc@yahoo.co.in

Date of Submission: 07/08/2013.

Date of Peer Review: 08/08/2013.

Date of Acceptance: 22/08/2013.

Date of Publishing: 27/08/2013 